On copyright

\section{Copyright in the networked world: sound publication}

\author{
Michael Seadle
}

\section{The author}

Michael Seadle is Editor of Library Hi Tech. He is also Digital Services and Copyright Librarian at Michigan State University.

\section{Keywords}

Copyright, Intellectual property, Law, Electronic publishing, Internet

\section{Abstract}

There are times when the US copyright laws seem to stem from a culture that puts little value on providing public access to its own past. Two recent conferences discussed problems raised by copyright laws for those interested in multimedia (especially sound) recordings. Part of the discussion focused on how to interpret the copyright status of pre-1972 sound recordings. One provision of the current law appears to throw all pre-1972 sound recordings into a uniquely old-fashioned situation where no federal copyright regulation applies until all protection ceases in 2067. Many common assumptions based on the 1976 law and on analogies from print may not hold up.

\section{Electronic access}

The research register for this journal is available at http://www.mcbup.com/research_registers

The current issue and full text archive of this journal is available at

http://www.emerald-library.com/ft

Library Hi Tech

Volume $19 \cdot$ Number $2 \cdot 2001 \cdot$ pp. 194-198

(C) MCB University Press $\cdot$ ISSN 0737-8831

\section{Introduction}

One of the things that everyone knows but no one can quite think how to demonstrate is that a country's politics reflect the design of its culture (Geertz, 1973, p. 311).

Certainly there are times when the US copyright laws seem to stem from a culture that puts little value on providing public access to its own past. This leaves librarians and archivists scrambling to search for loopholes and exemptions that let them make the country's cultural heritage available to a wider audience beyond the walls of their institutions. Recently two conferences at the Library of Congress the "Folk Heritage Collections in Crisis" conference in December, 2000, and the "Best Practices for Digital Sound" conference in January, 2001 - discussed problems raised by copyright laws for those interested in multimedia (especially sound) recordings.

At the latter meeting, part of the discussion focused on how to interpret the copyright status of pre-1972 sound recordings. The problem is essentially this:

Prior to February 15, 1972, the effective date of the Sound Recording Act of 1971, sound recordings did not enjoy the protection of federal copyright law (Field, 2000, p. 170).

That sounds potentially helpful for dissemination, but it is not. Lawyers interpret this situation in several different ways. One approach is to claim that rights issues reverted to applicable state laws:

Any agreements prior to February 15, 1972, granting work-for-hire status for sound recording and transferring full ownership to the record company are governed by applicable state law (Field, 2000, p. 170).

Another interpretation suggested at the meeting was to say that pre-1972 sound recordings should be treated as unpublished. Of course there are multiple layers of rights: the words of a speech might have been published in a conventional print form and questions still remain about the copyright in the recording of those words. For music the score and lyrics could be protected, and questions remain about the recording of the performance. To simplify, I

The author is not a lawyer and nothing in this column should be considered legal advice. 
will focus mainly on US made recordings of speeches and interviews - not plays - where the underlying words have no separate print existence (though the lack of a separate print existence can also be a complication).

\section{Are sound recordings unpublished works?}

Many non-lawyers at the meeting objected to the idea that a radio broadcast could be considered unpublished. The legal definition of publication is not necessarily intuitive.

Consider the following question: Is publication more like exhibiting an oil painting in a small private gallery, or like broadcasting a speech nationally on radio and television?

It seems reasonable that anything with a large, open-ended audience should fit somehow into the definition of publication, while exhibiting a work to a relatively small group probably should not be called publication. If publication depended on audience size, these intuitive judgments might be true, but size is not the test most courts have used. One of the most notable copyright cases involving a speech was the $1963 \mathrm{Mr}$ Maestro case, where Dr Martin Luther King sued the Mr Maestro company for infringing on his "I have a dream" speech:

Defendants stress the public nature of the delivery of the speech by Dr King - the enormous crowd, the radio and television broadcasts, the movie newsreel pictures. The question is: was this a general publication of the speech so as to place it in the public domain? (Nimmer et al., 1991, p. 165).

The court decided that it was not:

Statutory copyright may be obtained for "[1]ectures, sermons, addresses (prepared for oral delivery)". 17 U.S.C.A. $\S 5$ c. The copyright may be obtained before any publication of such works but as soon as the publication occurs there must be compliance with the requirements as to published works. 17 U.S.C.A. $\S \S 10,12$. Ordinarily the public performance of a work - such as the delivery of a speech or performance of a play - is not a publication (Nimmer et al., 1991, p. 164).

The idea was not new even then. The court cited precedent:

The broadcast by radio of a script is not a general publication of the work. Heim v. Universal Pictures Co., 154 F.2d 480 (2d Cir. 1946) (Nimmer et al., 1991, p. 165).
Ultimately the King case depended on whether the speech itself had been registered before it was disseminated in print form.

This case offers a different insight into the legal definition of copyright. The court is clear that merely exhibiting a painting does not necessarily constitute publication:

The public exhibition of a painting without notice of copyright in a gallery the rules of which forbade copying is not a general publication. Werckmeister v. American Lithographic Co., 134 F. 321, 68 L. R. A. 591 (2d Cir. 1904). In affirming in this case, the Supreme Court said: "One or many persons may be permitted to an examination under circumstances which show no intention to part with the property right, and it will remain unimpaired" (Nimmer et al., 1991, p. 165).

Having rules against copying at the exhibition are crucial:

We do not mean to say that the public exhibition of a painting or statue, where all might see and freely copy it, might not amount to publication within the statute, regardless of the artist's purpose or notice of reservation of rights which he takes no measure to protect (Nimmer et al., 1991, p. 170).

In other words, whether the painting had been published depended on whether others could legally make or obtain copies of the work. The definition of "publication" in the current US Copyright law affirms the importance of some form of transfer of ownership, either temporarily or permanently:

"Publication" is the distribution of copies or phonorecords of a work to the public by sale or other transfer of ownership, or by rental, lease, or lending. The offering to distribute copies or phonorecords to a group of persons for purposes of further distribution, public performance, or public display, constitutes publication. A public performance or display of a work does not of itself constitute publication (17 USC 101).

One of the reasons why broadcast (or other public performance) does not constitute publication is that it does not involve the transfer of ownership of a physical copy. Broadcast works have no substance, no physical medium. They exist for only a fleeting moment, then vanish into the ether for ever - at least in theory.

In fact recording devices preexisted radio broadcast. Edison invented his phonograph in 1878. Marconi was only four years old at the time, and did not claim his invention of the wireless until 1898. Early recording devices 
were not especially cheap or easy to use, but a wealth of old media in archives show that many people recorded broadcast news shows, songs, radio plays, even commercials. Michigan State University's Vincent Voice Library owns a large collection of pre-vinyl, double-sided, $33.3 \mathrm{rpm}$ records of New York city area broadcasts from the late 1940s. The donor made these recordings for private use (supposedly for a son in the military). They would seem to represent physical ownership of a work in much the same sense as making a photograph (i.e. a copy) of a painting in a private gallery. The radio stations appear to have broadcast no warnings against copying, and under the later (1984) Sony v. Universal City Studios ruling, making the recording for private use might reasonably be considered legal.

Does the existence of such a copy of a broadcast, plus the lack of a public notice against copying, parallel the situation with a painting cited above?

\section{The 1971 Sound Recording Act}

The 1971 Sound Recording act was the first Federal law that extended copyright protection to sound recordings. It resolved few questions and created new ones. The act limited its scope to particular rights:

Although arguments for protection of sound recordings had been asserted since the early part of the century, sound recordings were not recognized as "writings" and granted federal copyright protection as such until the Sound Recordings Act of 1971 [hereinafter $1971 \mathrm{Act}$ ], which was an amendment to the 1909 Act. Even then, only the rights of reproduction, distribution, and adaptation were granted to the owners of sound recordings (Leach, 2000, p. 204).

The act had been written mainly to serve as an anti-piracy measure for commercial recordings on physical media:

This was because the express purpose of the 1971 Act was merely to prevent phonorecord piracy, and Congress was reluctant to upset the existing commercial balance among affected parties. The right of public performance was not included because it was assumed that the aforementioned rights were sufficient to protect sound recordings from piracy (Leach, 2000, p. 204).
Public performance was a significant omission. The act seems to have focused only on recordings on physical media, which had a well established commercial value and an industry dedicated to their production and sales. Piracy for broadcasts had yet not become a significant issue.

Another question the act did not address was who actually owns the rights to sound recordings:

Furthermore, the 1971 Act specifically declined to fix authorship among producers, performers, and other parties to the creation of a sound recording, leaving this issue to be determined through employment and contractual relationships (Leach, 2000, p. 205).

Ambiguity in ownership plagues those who try to comply with the law by seeking an appropriate permission to use a work. It is not unusual for rights owners themselves not to be sure what (or how many) rights they own.

It may be important that the law did not try to prevent home recording:

Finally, according to the DPRSRA's House

Report, the 1971 Act was not intended to restrict home taping of sound recordings for noncommercial, private use (Leach, 2000, p. 205).

Copying the sound in this way for noncommercial use would seem to bear a striking resemblance to copying a painting with a photograph. But no case law suggests that this kind of copying has the same effect of turning an unpublished into a published work.

Reasoning by analogy does not always work.

Despite its flaws, this act brought an important range of commercial recordings under federal law and out of the chaos of state legislation, but it quite explicitly did nothing to clarify or alter the situation for pre-1972 recordings.

\section{The 1976 Copyright Law}

The 1976 law (which went into effect in 1978) made major changes in the duration and regulation of copyright, especially for unpublished materials. But the law quite explicitly did not apply to pre-1972 sound recordings:

(c) With respect to sound recordings fixed before February 15, 1972, any rights or remedies under 
the common law or statutes of any State shall not be annulled or limited by this title until February 15, 2067. The preemptive provisions of subsection (a) shall apply to any rights and remedies pertaining to any cause of action arising from undertakings commenced on or after February 15, 2067. Notwithstanding the provisions of section 303 , no sound recording fixed before February 15, 1972, shall be subject to copyright under this title before, on, or after February 15, 2067 (17 USC 301 (c)).

This provision appears to throw all pre-1972 sound recordings into a uniquely old-fashioned situation where no federal copyright regulation applies until all protection ceases in 2067 . The reason for this extraordinary exception is explained in the Historical and Revision notes:

A unique and difficult problem is presented with respect to the status of sound recordings fixed before February 12, 1972, the effective date of the amendment bringing recordings fixed after that date under Federal copyright protection. In its testimony during the 1975 hearings, the Department of Justice pointed out that under section 301 as then written: This language could be read as abrogating the anti-piracy laws now existing in 29 states relating to pre-February 15, 1972 sound recordings on the grounds that these statutes proscribe activities violating rights equivalent to ... the exclusive rights within the general scope of copyright. Certainly such a result cannot have been intended for it would likely effect the immediate resurgence of piracy of preFebruary 15, 1972, sound recordings (17 USC 301 Notes).

It is not clear that this concern was true, but both houses of Congress reacted. The Senate suggested leaving pre-1972 recordings under state or common law. The House recognized that this could lead to perpetual protection, which the constitution does not allow, and set an arbitrary date 75 years in the future (later changed to 95 years) when all protection would cease.

This provision raises far more questions about pre-1972 recordings than that it solves. Chief among these are:

- Which state laws apply, what are they, and how much do they really protect recordings? By now state laws have been revised many times since 1972 . Some may even have been deleted on the theory that federal copyright law had taken over.
Merely finding out what protections exist could become a significant research task.

- To what extent might Federal copyright exemptions such as fair use (17 USC 107) apply? Presumably the Federal statute embodying fair use would not, but the concept of fair use existed also in pre-1978 case law.

- To what extent, if any, does the question of publication apply? For example, is a live broadcast more an unpublished work than a sound recording? This matters because unpublished works can fall into the public domain as early as 2003, well ahead of the 2067 date in 17 USC 301.

- How much does any of this really apply to non-commercial spoken word material that was never sold to the general public on conventional recording media? The intent of the 1971 law seems focused clearly on record sales. Would the courts really apply it, for example, to a chance recording of a speech by President Woodrow Wilson published before 1923?

\section{Conclusions}

One thing at least has become clear to this nonlawyer about pre-1972 sound recordings: many of my past assumptions based on the 1976 law and on analogies from print may not hold up. For example, I had assumed that pre-1923 US sound recordings would have fallen safely into the public domain. That might have been 144 years too optimistic. I had also assumed (by analogy with Federal government documents) that recordings made by government officials on government business had no copyright protection. But that provision comes from Federal law, which might well not apply. As a librarian I had also applied the 17 USC 108 provision allowing certain kinds of libraries to keep and hold certain kinds of news broadcasts to pre-1972 news shows as well. That may be valid, or it may be undermined by 17 USC 301 (c).

The legal situation of pre-1972 recordings seems only to grow less clear the more it is examined. This is partly because no case law exists for many of the kind of unique noncommercial recordings that most interest 
libraries and archives. That could be good news for those who provide Web access to older materials based on a risk-assessment model, since it suggests little or no litigation. Those who wish simply to follow the law can be left having to make very conservative interpretations.

The fact is that many of the politicians who have written the copyright laws come from a culture which (quite reasonably) puts a premium on protecting the economic interests of those who create intellectual property. They have focused generally on commercial works, and problems relating to piracy. That was the case with the 1971 Sound Recording Act. Its basic intention was to create order within a federal system that balanced protection with time limits, exemptions for libraries, and a wellestablished concept of fair use. They succeeded with post-15 February 1972 material, but have left an uncomfortable legacy for those libraries and archives interested in providing Internet access to earlier sound recordings for legitimate educational and scholarly needs.

\section{References}

17 USC 301, United States Code, Title 17, Chapter 3, section 30

Field, C. (2000), "Their master's voice? Recording artists, bright lines, and Bowie bonds: the debate over sound recordings as works made for hire", Journal of the Copyright Society of the USA, Vol. 84 Nos 1-2, Fall-Winter, pp. 145-89.

Geertz, C. (1973), The Interpretation of Cultures, Basic Books, New York, NY.

Leach, E.D. (2000), "Everything you always wanted to know about digital performance rights but were afraid to ask", Journal of the Copyright Society of the USA, Vol. 84 Nos 1-2, Fall-Winter, pp. 191-291.

Nimmer, M., Marcus, P., Myers, D. and Nimmer, D. (1991), Cases and Materials on Copyright; and Other Aspects of Entertainment Litigation, Including Unfair Competition, Defamation, Privacy, 4th ed., West Publishing, St Paul, MN. 